\title{
Predictors of poor blood pressure control among Iranian hypertensive patients
}

\author{
Leila Jahangiry ${ }^{1,2}$, Jalileh Ghanbari ${ }^{1}$, Mahdieh Abbasalizad Farhangi ${ }^{3}$, Parvin Sarbakhsh ${ }^{4 *}$ and Koen Ponnet ${ }^{5,6}$
}

\begin{abstract}
Objective: The aim of this study is to investigate factors associated with poor blood pressure (BP) control in older hypertensive patients living in Iran. Poorly controlled hypertension was defined as blood pressure greater than or equal to $140 / 90 \mathrm{mmHg}$. Multiple logistic regressions were performed to identify factors associated with poor BP control.

Results: More than half of the patients (55.1\%) had poor control of hypertension. Multivariate logistic regression analysis showed that being over 60 years of age (OR 1.67; $95 \% \mathrm{Cl} 1.18-2.37 ; p=.003)$, being widowed or divorced (OR 1.56; 95\% Cl 1.03-2.35; $p=.035$ ], smoking (OR 1.78; 95\% Cl 1.07-2.65; $p=.01], \mathrm{BMI}>25 \mathrm{~kg} / \mathrm{m}^{2}$ (OR $1.5195 \%$ Cl 1.05-2.78), having a waist circumference $\geq 90 \mathrm{~cm}$ (OR 1.7; 95\% Cl 1.2-2.42; $p=.003$ ], the use of calcium channel blockers (OR 2.69; 95\% Cl 1.26-5.72; $p=.01]$, and the use of angiotensin converting enzyme inhibitors (OR 1.66; 95\% $\mathrm{Cl} 1.01-2.72 ; p=.044]$ contributed significantly to poor control of hypertension. Making a key BP control screening target (such as age over 60 and waist circumference of $90 \mathrm{~cm}$ or more) for cardiovascular specialists and other health care practitioners is needed for elderly patients at risk for poor BP control.
\end{abstract}

Keywords: Hypertension, Uncontrolled blood pressure, Patient, Cardiovascular diseases

\section{Introduction}

Hypertension is a common risk factor for cardiovascular disease and is a major health problem around the world. In addition, it is the most important single contributor to premature mortality [1-3]. It has been estimated that $22.1 \%$ of Iranian adults are hypertensive, and in most cases, their blood pressure is uncontrolled [4].

Poor control of blood pressure could augment cardiovascular risks, stroke, and myocardial infarction, which can be catastrophic to individuals and results in increasing costs for health care systems [5]. The role of systolic blood pressure (SBP) as an important predictor for cardiovascular risk has been demonstrated in several studies [6]. For instance, a recent study provided evidence that each $10 \mathrm{mmHg}$ reduction in usual SBP is associated with a significant $11 \%$ reduction in the risk of myocardial infarction [7].

\footnotetext{
${ }^{*}$ Correspondence: p.sarbakhsh@gmail.com

${ }^{4}$ Epidemiology and Biostatistics Department, School of Public Health,

Tabriz University of Medical Sciences, Tabriz, Iran

Full list of author information is available at the end of the article
}

Because the need to control and to manage hypertension is well recognized, primary health care systems are on the front lines. They can provide screening programs for early detection, manage regular contacts with patients, apply preventive measures, and deliver consistent and persistent care for patients with hypertension [8]. However, it is important to identify the factors that influence BP control in hypertensive patients. Previous studies found that low adherence to medication use [9], an unhealthy lifestyle [10], competing priorities, and provider inertia [11] contribute to the poor control of BP. On the other hand, screening, diagnosis, treatment, and successful control of hypertension are difficult to catch, especially among older hypertensive patients. Adding another level of complexity to this public health problem, demographic variation and increasing prevalence of hypertension by age make this condition one of the major health policy challenges [12]. Approximately $50 \%$ of patients with hypertension drop out of health care within the first year of diagnosis, and only $25-34 \%$ of them comply with antihypertensive treatment and have controlled BP [13]. 
It is therefore important to identify factors that could affect $\mathrm{BP}$ control among older hypertensive patients. The aim of this study is to investigate factors that may influence poor BP control in older hypertensive patients and to identify patients' characteristics associated with poor control of BP in order to improve the management and care of these patients.

\section{Main text \\ Methods}

This cross-sectional study was conducted in Takab, West Azerbaijan province, Iran. A total of 750 patients with a diagnosis of hypertension in primary health care centers were randomly recruited from August 2016 to February 2017. The inclusion criteria were: (1) having been diagnosed with hypertension in the previous 6 months, (2) being 50 years old or above, and (3) having a household health record in one of the Takab health care centers. Subjects who have diabetes and a cognitive disorder were not eligible.

Patients who had been referred to health care centers were randomly selected and contacted by telephone for eligibility. During the phone interview, eligible patients who were interested in participating in the study were asked to come to the health centers for a clinical assessment by a trained health care researcher. The response rate was $83.3 \%$ (750/900).

Data were collected by administering a questionnaire. The questions related to the participants' sociodemographic characteristics, treatment for hypertension, medical history, and current cigarette smoking habits followed the guidelines provided by the American college of cardiology [14]. Furthermore, patients' blood pressure (BP), waist circumference (WC), weight, and body mass index (BMI) were also recorded. BP was measured with a mercury sphygmomanometer, twice in the same arm, after the participant had been seated at rest for 10-15 min. The systolic and diastolic BP measurements were the mean of the two readings. WC was evaluated using a measuring tape to the nearest $.1 \mathrm{~cm}$. The weight of an individual dressed in light clothing without shoes was recorded each time using a calibrated scale to the nearest $.1 \mathrm{~kg}$. Height was measured without shoes using a stadiometer to the nearest $.1 \mathrm{~cm}$. BMI was measured by the individual's weight in kilograms divided by the square of his/her height in meters [15].

Consistent with [16], uncontrolled hypertension was defined as systolic blood pressure $\geq 140 \mathrm{mmHg}$ and/or diastolic blood pressure $\geq 90 \mathrm{mmHg}$ for patients that currently taking antihypertensive medication. Antihypertensive treatment information was asked from patients and in the absence of patients information, it was derived from household health records (Additional file 1).
Statistical analyses were conducted using the STATA release 14.0 software (College Station, Texas, USA). Data were presented using frequencies (percentages) for categorical variables and means for numeric variables. Descriptive statistics were calculated to compare the characteristics of patients with controlled and uncontrolled hypertension. Between-group differences were calculated using $X^{2}$ or Student's t tests. A series of t tests and multiple logistic regressions were performed to compute odds ratios (ORs) and their confidence intervals. In the univariate analyses, demographic and anthropometric factors were entered separately. $\mathrm{p}$ values below .05 were considered to be significant.

\section{Results}

The sociodemographic and clinical characteristics of the hypertensive patients are shown in Table 1 . The mean age of the 750 patients was 65.4 years, and $56.1 \%$ were women. More than half $(55 \%, n=413)$ of the patients had uncontrolled hypertension. There were significant marital status differences between patients with controlled and uncontrolled BP. Significant differences between patients with controlled and uncontrolled hypertension were found for BMI, weight, WC, years living with hypertension and comorbidities in hypertension $(p<.05$ for all $)$.

Table 2 provides information about patients' medication use based on antihypertensive drug class. The most common medications used are angiotensin converting enzyme inhibitors (ACEIs, 37.9\% of the patients), followed by angiotensin receptor blockers (ARBs, 14.9\%), $\beta$-blockers (12.4\%), diuretics (9.7\%), and calcium channel blockers (CCBs, 3.9\%). Almost all patients (99.9\%) were receiving antihypertensive medication, and only $44 \%$ of the patients achieved controlled BP.

The results of the multivariate analyses of factors predicting poor BP control are shown in Table 3. Multivariate logistic regression analysis showed that the following factors were significantly associated with uncontrolled blood pressure control: being 60 years old or above (OR 1.67; 95\% CI 1.18-2.37; $p=.003)$, being widowed or divorced (OR 1.56; 95\% CI 1.03-2.35; $p=.035$ ), smoking (OR 1.69; 95\% CI 1.07-2.65; $p=.023$ ), BMI > $25 \mathrm{~kg} /$ $\mathrm{m}^{2}$ (OR $1.5195 \%$ CI 1.05-2.78), having a waist circumference of $90 \mathrm{~cm}$ or more (OR 1.7; 95\% CI 1.2-2.42; $p=.003$ ), using CCBs (OR 2.69; 95\% CI 1.26-5.72; $p=.01$ ), and using ACEIs (OR 1.66; 95\% CI 1.01-2.72; $p=.044)$.

\section{Discussion}

The study presents an analysis of factors that may be associated with poor BP control in hypertensive patients in Takab, West Azerbaijan province, Iran. The findings 
Table 1 Descriptive characteristics of hypertensive patients

\begin{tabular}{|c|c|c|c|c|}
\hline $\begin{array}{l}\text { Parameters } \\
\text { Categorical variables }\end{array}$ & $\begin{array}{l}\text { Controlled BP } \\
N(\%)\end{array}$ & $\begin{array}{l}\text { Uncontrolled BP } \\
\mathrm{N}(\%)\end{array}$ & $\begin{array}{l}\text { Total } \\
\text { N (\%) }\end{array}$ & p value \\
\hline Gender & 337 & 413 & & .980 \\
\hline Male & $148(43.9)$ & $181(43.8)$ & $329(43.9)$ & \\
\hline Female & $189(56.1)$ & $232(56.2)$ & $421(56.1)$ & \\
\hline Marital status & & & & .048 \\
\hline Married & $275(81.6)$ & $304(73.6)$ & $579(77.2)$ & \\
\hline Single & $4(1.2)$ & $2(.48)$ & $6(.8)$ & \\
\hline Widow & $55(16.3)$ & $100(24.2)$ & $155(20.66)$ & \\
\hline Divorced & $3(.9)$ & $7(1.7)$ & $10(1.3)$ & \\
\hline Education & & & & .207 \\
\hline Illiterate & $237(81.6)$ & $311(75.3)$ & $548(73.1)$ & \\
\hline Elementary school & $90(26.7)$ & $97(23.5)$ & $187(24.9)$ & \\
\hline High school and university & $6(1.8)$ & $3(.7)$ & $9(1.2)$ & \\
\hline Economic status & & & & .671 \\
\hline Low & $147(43.6)$ & $168(40.6)$ & $315(42)$ & \\
\hline Intermediate & $139(41.2)$ & $177(42.8)$ & $316(42.1)$ & \\
\hline High & $51(15.2)$ & $68(16.4)$ & $119(15.8)$ & \\
\hline Comorbidities of hypertension (yes) & $72(21.3)$ & $130(31.4)$ & $202(26.9)$ & .002 \\
\hline Mental & $9(12.5)$ & $20(15.4)$ & $29(14.3)$ & \\
\hline Coronary Heart Disease & $26(31.7)$ & $56(68.3)$ & $82(40.6)$ & \\
\hline Cancer & 0 & $2(1.5)$ & $2(.9)$ & \\
\hline Respiratory diseases & $12(16.6)$ & $21(16.2)$ & $33(16.3)$ & \\
\hline Urologic diseases & $6(8.3)$ & $5(3.8)$ & $11(5.4)$ & \\
\hline Arthritis & $12(16.6)$ & $17(13.1)$ & $29(14.3)$ & \\
\hline Thyroid disease & $1(1.3)$ & $1(.7)$ & $2(.9)$ & \\
\hline Osteoporosis & $2(2.6)$ & $2(1.4)$ & $4(1.8)$ & \\
\hline Eye diseases & $1(1.3)$ & $3(2.3)$ & $4(1.8)$ & \\
\hline Gastritis & 3 & $3(2.3)$ & $6(2.9)$ & \\
\hline Parameters & Controlled BP & Uncontrolled BP & Total & $p$ value \\
\hline Continuous variables & Mean (SD) & Mean (SD) & Mean (SD) & \\
\hline Age (years) & $64.7(9.8)$ & $65.9(9.5)$ & $65.4(9.7)$ & .094 \\
\hline BMI $\left(\mathrm{kg} / \mathrm{m}^{2}\right)$ & $26(4.4)$ & $27.4(4.5)$ & $26.8(4.5)$ & $<.0001$ \\
\hline Weight (kg) & $67.5(12.2)$ & $70.9(12.5)$ & $69.36(12.5)$ & $<.0001$ \\
\hline WC & $92.5(12.3)$ & $96.9(11)$ & $94.8(12.6)$ & $<.0001$ \\
\hline $\mathrm{SBP}(\mathrm{mmHg})$ & $125.9(8.7)$ & $147.1(15.5)$ & $137.6(16.6)$ & $<.0001$ \\
\hline $\mathrm{DBP}(\mathrm{mmHg})$ & $77.4(6)$ & $92.2(8.8)$ & $85.5(10.6)$ & $<.0001$ \\
\hline Years living with hypertension & $7.6(4.4)$ & $8.4(4.4)$ & $8.04(4.5)$ & .018 \\
\hline
\end{tabular}

$B M I$ body mass index, WC waist circumference, $S B P$ systolic blood pressure, $D B P$ diastolic blood pressure

from this study revealed that only $44.9 \%$ of the patients had adequate BP control [16]. A similar study from China indicated that nearly $95 \%$ of patients were receiving antihypertensive medication, and that only $16.7 \%$ of women and $19.1 \%$ of men had adequate BP control [17]. Although adequate control of BP is a cornerstone in stroke prevention and coronary events, our findings indicate that BP control cannot be achieved by more than half of the patients $(55.1 \%)$. The rates of control of hypertensive patients in our study were higher than the $48 \%$ control rate in the United States of America that reported in a NHANES study [18]. Therefore, it is important to identify factors that influence poor BP control among hypertensive patients.

Results from the multivariate logistic regression analysis revealed that being older than 60 years, being 
Table 2 Medication use among hypertensive patients based on antihypertensive drug class

\begin{tabular}{lccr}
\hline Medication use & Controlled BP & Uncontrolled BP & Total \\
& $\mathbf{3 3 7}$ & $\mathbf{4 1 3}(\mathbf{5 5 . 1 )}$ & $\mathbf{7 5 0}$ \\
\hline CCB & $10(34.5)$ & $19(65.5)$ & 29 \\
ACEI & $111(39.1)$ & $173(60.9)$ & 284 \\
$\beta$-blockers & $43(46.2)$ & $50(53.8)$ & 93 \\
ARB & $58(51.8)$ & $54(48.2)$ & 112 \\
Diuretics & $45(61.6)$ & $28(38.4)$ & 73 \\
Diuretics + ARB & $8(28.6)$ & $20(71.4)$ & 28 \\
Diuretics + CCB & $2(20)$ & $8(80)$ & 10 \\
Diuretics + ARB + ACEI & $4(36.4)$ & $7(63.6)$ & 11 \\
$\beta$-blockers + ACEI & $24(66.7)$ & $12(33.3)$ & 36 \\
$\beta$-blockers + ARB & $5(31.3)$ & $11(68.8)$ & 16 \\
$\beta$-blockers + Diuretics & $12(63.2)$ & $7(36.8)$ & 19 \\
Diuretics + ACEI & $13(41.9)$ & $18(58.1)$ & 31 \\
ACEl + CCB & $1(14.3)$ & $6(85.7)$ & 7 \\
\hline ACEl & &
\end{tabular}

$A C E l$ angiotensin converting enzyme inhibitor, $A R B$ angiotensin receptor blocker, $C C B$ calcium channel blockers

Table 3 Multivariate model predicting blood pressure control among patients with hypertension

\begin{tabular}{|c|c|c|c|}
\hline & OR & $95 \% \mathrm{Cl}$ & $\mathrm{p}$ value \\
\hline \multicolumn{4}{|l|}{ Age in years (ref $\leq 60)$} \\
\hline$>60$ & 1.67 & $1.18-2.37$ & .003 \\
\hline \multicolumn{4}{|l|}{ Gender (ref $=$ female) } \\
\hline Male & .79 & $.85-1.98$ & .226 \\
\hline \multicolumn{4}{|c|}{ Married status $($ ref $=$ married $)$} \\
\hline Single & .54 & $.084-3.5$ & .522 \\
\hline Widowed/divorced & 1.56 & $1.03-2.35$ & .035 \\
\hline Smoking (yes) & 1.78 & $1.07-2.65$ & .010 \\
\hline Comorbidity & 1.32 & $.77-2.46$ & .329 \\
\hline Weight & 1.01 & $.99-1.03$ & .21 \\
\hline \multicolumn{4}{|l|}{ BMI $($ ref $\leq 25$ kg/m²) } \\
\hline $26-30 \mathrm{~kg} / \mathrm{m}^{2}$ & 1.51 & $1.05-2.78$ & .025 \\
\hline$>30 \mathrm{~kg} / \mathrm{m}^{2}$ & 1.63 & $1.02-2.61$ & .040 \\
\hline \multicolumn{4}{|c|}{ Waist circumference in $\mathrm{cm}(\mathrm{ref} \leq 90)$} \\
\hline$\geq 90$ & 1.7 & $1.2-2.42$ & .003 \\
\hline Living with hypertension & 1.24 & $.76-2.01$ & .39 \\
\hline \multicolumn{4}{|l|}{ Medication use } \\
\hline $\mathrm{CCB}$ & 2.69 & $1.26-5.72$ & .01 \\
\hline ACEI & 1.66 & $1.01-2.72$ & .044 \\
\hline$\beta$-blockers & 1.037 & $.62-1.7$ & .89 \\
\hline ARB & 1.36 & $.84-2.21$ & .2 \\
\hline Diuretics & .94 & $.57-1.55$ & .82 \\
\hline
\end{tabular}

$A C E l$ angiotensin converting enzyme inhibitor, $A R B$ angiotensin receptor blocker, $C C B$ calcium channel blockers

widowed or divorced, smoking, having a waist circumference of $90 \mathrm{~cm}$ or more, the use of CCBs, and the use of ACEIs contribute to poor control of hypertension. The finding that being 60 years old or above is associated with higher odds of uncontrolled BP is consistent with previous studies [19]. One major reason for this poor management of BP is that the severity of hypertension increases markedly with advancing age [20]. Furthermore, because $\mathrm{BP}$ control is difficult in elderly patients and represents a management dilemma, it seems that categorizing hypertensive patients into $\geq 60$ and $<60$ years might be a key $\mathrm{BP}$ control screening target for cardiovascular specialists and other practitioners in health care settings. Ideally, older patients with hypertension should be followed up on every 3-6 months and continue to assess their adherence to medication use for BP control [21]. Also, more efforts, such as public health education and a blood pressure monitoring system, should be included for the older age group.

In this study, we found a significant association between poor BP control and being widowed or divorced, which is consistent with other studies [22, 23]. This finding may be related to the absence of partner support, which often results in lower health outcomes through health risk behaviors and stress [22]. Consistent with our results, Idler et al. [15] highlighted a strong protective effect of spouses in caregiving (both male and female) on survival for up to 5 years following surgery. This suggests that social spousal support, more so than lifestyle behaviors and medicine use, produces health benefits. Social support can benefit patients' health by buffering stress, improving self-efficacy, and increasing healthy behavior $[9,24]$. In fact, a meta-analysis study found that adherence was $27 \%$ higher when patients had practical support available to them. However, inconsistent with our results, there is also evidence that a spouse or partner does not reduce uncontrolled hypertension, suggesting that further research is needed regarding the role of spouses in the management of hypertension conditions [25].

Another factor that affected poor BP control is smoking. This result confirms that smoking acutely increases blood pressure due to an increase in both cardiac output and total peripheral vascular resistance [26]. Alternatively, smoker patients are more sedentary and have less healthy diets, both of which are factors that can directly raise $\mathrm{BP}$ and result in failure in $\mathrm{BP}$ control [27].

The relationship between waist circumference and hypertension has been clearly established [28]. In the present study, the likelihood of poor BP control was increased when the waist circumference was $90 \mathrm{~cm}$ or more (i.e., the cut-off point for the Iranian abdominal obesity definition) [29]. According to the findings of our study, an increase in waist circumference significantly increases the probability of poor BP control. This finding confirms that the impact of abdominal obesity on the 
control of hypertension is an important risk factor [30, 31].

All of the patients had been treated with antihypertensive drugs for an average of 8.04 years prior to study enrollment. Our findings suggest that poor control of blood pressure is also significantly associated with the use of CCBs and ACEIs, which is consistent with the findings of a study by Xu et al. [17]. However, some studies have shown improvements in the outcomes among patients with coronary heart disease using dihydropyridine CCBs $[32,33]$. Although non-dihydropyridine CCBs are taken more often by uncontrolled than controlled hypertensive patients, they have marked negative inotropic effects [34]. Consistent with a previous study [34], our findings align with the efficacy of diuretics and reninangiotensin system blockers, especially when they are taken in combination.

Hypertension surveillance could be used more frequently in daily practice in primary care to identify at-risk individuals. As such, it is important to make hypertensive patients and their families aware of the risk factors of uncontrolled BP. The results of the present study indicate the need for greater efforts at safe, effective strategies in order to achieve controlled BP among the oldest patients with hypertension. BP control may be related to factors beyond medication adherence, including lifestyle factors, social support, and the ability to navigate the health care system effectively, though this requires further study. In addition, the failure of antihypertensive medication to adequately control BP is determined by both the patients' characteristics and factors related to the medication. The findings of this study indicate that treating elderly hypertensive patients will reduce the risk of cardiovascular events. There is evidence that hypertension treatment reduces the incidence of cognitive impairment and dementia in the elderly [35].

\section{Limitations}

This study was cross-sectional, and could not determine causality. Another limitation was potential measurement error for the medication use. There wasn't any information on actual adherence to high blood pressure medication use and treatment.

\section{Additional file}

Additional file 1. Demographic questionnaire and personal information.

\section{Abbreviations}

BP: blood pressure; sbp: systolic blood pressure; wc: waist circumference; bmi: body mass index; or: odds ratios; aceis: angiotensin converting enzyme inhibitors; arbs: angiotensin receptor blockers; ccbs: calcium channel blockers.

\section{Authors' contributions}

$L J$ and $J G H$ were responsible for the study design. $L J$ and PS did the analyses. $\mathrm{LJ}, J \mathrm{GH}$ and MAF were responsible for data interpretation. KP helped in the study design, prepared and edited the manuscript. All authors read and approved the final manuscript.

\section{Author details}

${ }^{1}$ Health Education and Health Promotion Department, School of Public Health, Tabriz University of Medical Sciences, Tabriz, Iran. ${ }^{2}$ Tabriz Health Services Management Research Center, Tabriz University of Medical Sciences, Tabriz, Iran. ${ }^{3}$ Department of Community Nutrition, Faculty of Health and Nutrition, Tabriz University of Medical Sciences, Tabriz, Iran. ${ }^{4}$ Epidemiology and Biostatistics Department, School of Public Health, Tabriz University of Medical Sciences, Tabriz, Iran. ${ }^{5}$ Department of Communication Sciences, MICT-IMEC, Faculty of Political and Social Sciences, Ghent University, Ghent, Belgium. ${ }^{6}$ Faculty of Social Sciences, University of Antwerp, Antwerp, Belgium.

\section{Acknowledgements}

We acknowledge the contributions of Tabriz University of Medical Sciences, Tabriz, Iran for providing facilities to the study.

\section{Competing interests}

The authors declare that they have no competing interests.

Availability of data and materials

The data are available from the authors.

Consent for publication

Not applicable.

\section{Ethics approval and consent to participate}

The study received ethical approval from the Ethics Committee of Tabriz University of Medical Sciences (NO: IR.TBZMED.REC.1395.13). We obtained written informed consent from all participants.

\section{Funding}

There is no funding resource.

\section{Publisher's Note}

Springer Nature remains neutral with regard to jurisdictional claims in published maps and institutional affiliations.

Received: 19 September 2017 Accepted: 21 November 2017

Published online: 04 December 2017

References

1. Poulter NR, Prabhakaran D, Caulfield M. Hypertension. Lancet. 2015:386:801-12

2. Song Y, Liu X, Zhu X, Zhao B, Hu B, Sheng X, Chen L, Yu M, Yang T, Zhao J. Increasing trend of diabetes combined with hypertension or hypercholesterolemia: NHANES data analysis 1999-2012. Sci Rep. 2016;6:36093.

3. Haghdoost AA, Sadeghirad B, Rezazadehkermani M. Epidemiology and heterogeneity of hypertension in Iran: a systematic review. Arch Iran Med. 2008;11:444-52.

4. Malekzadeh MM, Etemadi A, Kamangar F, Khademi H, Golozar A, Islami F, Pourshams A, Poustchi H, Navabakhsh B, Naemi M. Prevalence, awareness and risk factors of hypertension in a large cohort of Iranian adult population. J Hypertens. 2013;31:1364.

5. Tollman SM, Kahn K, Sartorius B, Collinson MA, Clark SJ, Garenne ML. Implications of mortality transition for primary health care in rural South Africa: a population-based surveillance study. Lancet. 2008;372:893-901.

6. Juraschek SP, Kovell LC, Miller ER, Gelber AC. Dose-response association of uncontrolled blood pressure and cardiovascular disease risk factors with hyperuricemia and gout. PLOS ONE. 2013;8:e56546.

7. Adler Al, Stratton IM, Neil HAW, Yudkin JS, Matthews DR, Cull CA, Wright AD, Turner RC, Holman RR. Association of systolic blood pressure with 
macrovascular and microvascular complications of type 2 diabetes (UKPDS 36): prospective observational study. BMJ. 2000;321:412-9.

8. Khatib R, Schwalm J-D, Yusuf S, Haynes RB, McKee M, Khan M, Nieuwlaat R. Patient and healthcare provider barriers to hypertension awareness, treatment and follow up: a systematic review and meta-analysis of qualitative and quantitative studies. PLoS ONE. 2014;9:e84238.

9. Morris AB, Li J, Kroenke K, Bruner-England TE, Young JM, Murray MD. Factors associated with drug adherence and blood pressure control in patients with hypertension. Pharmacother J Hum Pharmacol Drug Ther. 2006;26:483-92

10. Ham OK, Yang SJ. Lifestyle factors associated with blood pressure control among those taking antihypertensive medication. Asia Pac J Public Health. 2011;23:485-95.

11. O'connor PJ. Overcome clinical inertia to control systolic blood pressure. Arch Intern Med. 2003;163:2677-8.

12. James PA, Oparil S, Carter BL, Cushman WC, Dennison-Himmelfarb C, Handler J, Lackland DT, LeFevre ML, MacKenzie TD, Ogedegbe O. 2014 evidence-based guideline for the management of high blood pressure in adults: report from the panel members appointed to the Eighth Joint National Committee (JNC 8). JAMA. 2014:31:507-20.

13. Sabaté E. Adherence to long-term therapies: evidence for action. Geneva: World Health Organization; 2003.

14. Cannon CP, Battler A, Brindis RG, Cox JL, Ellis SG, Every NR, Flaherty JT, Harrington RA, Krumholz HM, Simoons ML, et al. American College of Cardiology key data elements and definitions for measuring the clinical management and outcomes of patients with acute coronary syndromes 333: a report of the American College of Cardiology Task Force on Clinical Data Standards (Acute Coronary Syndromes Writing Committee) Endorsed by the American Association of Cardiovascular and Pulmonary Rehabilitation, American College of Emergency Physicians, American Heart Association, Cardiac Society of Australia \& New Zealand, National Heart Foundation of Australia, Society for Cardiac Angiography and Interventions, and the Taiwan Society of Cardiology. J Am Coll Cardiol. 2001;38:2114-30

15. Idler EL, Boulifard DA, Contrada RJ. Mending broken hearts. J Health Soc Behav. 2012;53:33-49.

16. Chobanian AV, Bakris GL, Black HR, Cushman WC, Green LA, Izzo JL Jr, Jones DW, Materson BJ, Oparil S, Wright JT Jr. The seventh report of the joint national committee on prevention, detection, evaluation, and treatment of high blood pressure: the JNC 7 report. JAMA. 2003;289:2560-71.

17. Xu D, Chen W, Li X, Zhang Y, Li X, Lei H, Wei Y, Li W, Hu D, Wedick NM, et al. Factors associated with blood pressure control in hypertensive patients with coronary heart disease: evidence from the Chinese Cholesterol Education Program. PLoS ONE. 2013;8:e63135.

18. Gillespie CD, Hurvitz KA, Control CfD, Prevention. Prevalence of hypertension and controlled hypertension-United States, 2007-2010. MMWR Surveill Summ. 2013;62(Suppl 3):144-8.

19. Pinto E. Blood pressure and ageing. Postgrad Med J. 2007;83(976):109-14.

20. Lloyd-Jones DM, Evans JC, Levy D. Hypertension in adults across the age spectrum: current outcomes and control in the community. JAMA. 2005;294:466-72.

21. Nguyen QT, Anderson SR, Sanders L, Nguyen LD. Managing hypertension in the elderly: a common chronic disease with increasing age. Am Health Drug Benefits. 2012;5:146-53.

22. Wang H. Effects of marital status and transition on hypertension in Chinese women: a longitudinal study. In: [Unpublished] 2005. Presented at the 2005 Annual Meeting of the Population Association of America Philadelphia Pennsylvania March 31-April 2, 2005. Philadelphia.

23. Al-Ghuzi AAS, Al-Asadi JN. Prevalence and socio-demographic determinants of hypertension in Thi-Qar Governorate: a household survey. Am J Adv Drug Deliv. 2014;2:802-15.

24. DiMatteo MR. Social support and patient adherence to medical treatment: a meta-analysis. Health Psychol. 2004;23:207-18.

25. Cornwell EY, Waite LJ. Social network resources and management of hypertension. J Health Soc Behav. 2012;53:215-31.

26. Omvik P. How smoking affects blood pressure. Blood Press. 1996;5:71-7.

27. Kvaavik E, Meyer HE, Tverdal A. Food habits, physical activity and body mass index in relation to smoking status in 40-42 year old Norwegian women and men. Prev Med. 2004;38:1-5.

28. Rahmouni K. Obesity-associated hypertension: recent progress in deciphering the pathogenesis. Hypertension. 2014;64:215-21.

29. Azizi F, Khalili D, Aghajani H, Esteghamati A, Hosseinpanah F, Delavari A, Larijani B, Kelishadi R, Hadaegh F. Appropriate waist circumference cut-off points among Iranian adults: the first report of the Iranian National Committee of Obesity. Arch Iran Med. 2010;13:243.

30. Landsberg L, Aronne LJ, Beilin LJ, Burke V, Igel LI, Lloyd-Jones D, Sowers J. Obesity-related hypertension: pathogenesis, cardiovascular risk, and treatment. J Clin Hypertens. 2013;15:14-33.

31. Redón J, Cea-Calvo L, Moreno B, Monereo S, Gil-Guillén V, Lozano JV, Martí-Canales JC, Llisterri JL, Aznar J, Fernández-Pérez C. Independent impact of obesity and fat distribution in hypertension prevalence and control in the elderly. J Hypertens. 2008;26:1757-64.

32. Pitt B, Byington RP, Furberg CD, Hunninghake DB, Mancini GJ, Miller $M E$, Riley W, Investigators P. Effect of amlodipine on the progression of atherosclerosis and the occurrence of clinical events. Circulation. 2000;102:1503-10.

33. Collaboration BPLTT. Effects of different blood-pressure-lowering regimens on major cardiovascular events: results of prospectively-designed overviews of randomised trials. Lancet. 2003;362:1527-35.

34. Egan BM, Zhao Y, Axon RN, Brzezinski WA, Ferdinand KC. Uncontrolled and apparent treatment resistant hypertension in the United States, 1988 to 2008. Circulation. 2011. https://doi.org/10.1161/ CIRCULATIONAHA.111.030189.

35. Lionakis N, Mendrinos D, Sanidas E, Favatas G, Georgopoulou M. Hypertension in the elderly. World J Cardiol. 2012;4:135-47.

\section{Submit your next manuscript to BioMed Central and we will help you at every step:}

- We accept pre-submission inquiries

- Our selector tool helps you to find the most relevant journal

- We provide round the clock customer support

- Convenient online submission

- Thorough peer review

- Inclusion in PubMed and all major indexing services

- Maximum visibility for your research

Submit your manuscript at www.biomedcentral.com/submit 